\title{
Are Meeting Presentations a Springboard to Publication?
}

Arch G. Mainous III, PhD; John Saultz, MD

(Fam Med. 2021;53(9):749-50.)

doi: 10.22454/FamMed.2021.945009

$\mathbf{E}$ very year scholars from around the world attend scientific meetings. In the case of American family medicine, our most important academic meetings are the annual meetings of the Society of Teachers of Family Medicine (STFM) and the North American Primary Care Research Group (NAPCRG). Many of us also attend the annual Residency Leadership Summit sponsored by the American Academy of Family Physicians (AAFP) and the Association of Family Medicine Residency Directors. Some of us also present at the AAFP Annual Scientific Assembly or at AAFP state chapters meetings. Young faculty are encouraged to attend and present at these meetings; having presentations accepted by the meetings' peer review process is considered an important professional accomplishment. Some of these presentations are purely pedagogic while others share interim or final results of original research.

For years, we have encouraged presenters to submit papers based on their meeting presentations to peer-reviewed journals. But presentation and publication are two very different forms of scholarship. Purely pedagogic presentations are rarely suitable for publication. Although they can be enlightening and innovative examples of outstanding teaching, they usually offer little proof of effectiveness. On the other hand, original research reaches a far larger and more diverse audience when it is published in a medical journal than when it is presented at a meeting, and publication creates a permanent searchable document in the National Library of Medicine's Medline index. There are many reasons to present original research at scientific conferences. It is a great way to share with colleagues and can provoke discussions about the implications and next steps of your research. It is also a great faculty development opportunity for junior faculty helping them to focus their thoughts and react to questions from colleagues. But does presenting research at a meeting lead to publication? Traditional wisdom in academic medicine has considered peer-reviewed research presentations at scientific meetings to be the first step in a virtuous cycle that that leads to peer-reviewed publications, and eventually to grant funding for the next research study. Future meeting presentations and publication of findings from the subsequent study then continue this cycle. How often does this really happen?

The lead article in this issue of Family Medicine is another in a series of studies ${ }^{1-4}$ that suggests that it usually does not. Maxime Pautrat, MD, and colleagues found that about one-third of the presentations at two French general practice meetings ultimately were published. ${ }^{5}$ The results were a bit better (56\%) for presentations at European General Practice Research Network meetings. These findings agree with previous work in family medicine and in other medical specialties; the publication rate of scholarship presented at scientific meetings is $50 \%$ or less. Of course, some of the presentations at these meetings are not original research, but even research presentations can be challenging to transform into publishable papers. Perhaps we need to reconsider our traditional wisdom. Maybe we should stop

From the Department of Health Services Research, Management and Policy, and Department of Community Health and Family Medicine, University of Florida, Gainesville, FL (Dr Mainous); and Department of Family Medicine, Oregon Health \& Science University, Portland, OR (Dr Saultz). 
thinking of meeting presentations as the first step in a cycle. Maybe it is time to reconsider the goals of our scientific meetings and to view meeting presentations in a new context.

There are many benefits of attending scientific conferences. The modest proportion of presentations ultimately being published in peer-reviewed journals should not lead us to believe that quality research is not presented at such meetings. High-quality research is presented by experienced investigators at every STFM and NAPCRG meeting. Some of this innovative work will be a first step in the cycle of presentation to publication to grant funding and back to presentation. But other presentations will be pilot studies presented to gain experience and find collaborators. Such studies might be small in scale or limited in scope. For some investigators, publication is not the goal. A key benefit of presenting and hearing presentations of original research at scientific meetings is the ability to network in real time with colleagues. Questions that arise during a presentation can move the discipline forward by highlighting the implications of the work, the next steps in a research program, and potential collaborations. This is an invaluable experience for both junior faculty and experienced investigators. Even when experienced investigators are realistic about study weaknesses, presentations are a forum for feedback. Junior faculty can feel good about being accepted by peers and join the club by presenting their work. All research presenters must know their own research well enough to answer questions and respond to feedback about it. Being able to accept critical feedback is a crucial step in professional development.

As we move more and more toward team science, it is important to consider the professionalizing function and opportunities for networking, sharing ideas and collaboration that are provided by presenting research at scientific meetings. We have plenty of evidence to show that only a portion of presentations will become publications. We need a different lens to evaluate presentations at scientific meetings, a lens that sees the activity of presenting original research as a goal in itself.

\section{References}

1. Elder NC, Blake RL Jr. Publication patterns of presentations at the Society of Teachers of Family Medicine and North American Primary Care Research Group annual meetings. Fam Med. 1994;26(6):352-355

2. Post RE, Mainous AG III, O'Hare KE, King DE, Maffei MS. Publication of research presented at STFM and NAPCRG conferences. Ann Fam Med. 2013;11(3):258-261. doi:10.1370/ afm.1503

3. Van Royen P, Sandholzer H, Griffiths F, et al. Are presentations of abstracts at EGPRN meetings followed by publication? Eur J Gen Pract. 2010;16(2):100-105. doi:10.3109/138 14788.2010.482582

4. Schulte TL, Huck K, Osada N, et al. Publication rate of abstracts presented at the Annual Congress of the Spine Society of Europe (years 2000-2003). Eur Spine J. 2012;21(10):2105-2112. doi:10.1007/s00586-012-2211-5

5. Pautrat M, Tenot M, Lebeau JP. A publication rate comparison of oral communications presented at the 2010 and 2015 French General Practice congresses and European General Practice Network meetings. Fam Med. 2021;53(9):754-759. doi: 10.22454/FamMed.2021.447144

\section{Family Medicine Journal Seeks Editor in Chief Beginning in 2022}

John Saultz, MD, Family Medicine Editor in Chief, completes his final term in May of 2022 for a total of 12 years as editor. We are indebted to him for his exemplary service and significant contributions to our discipline, research community, and to STFM.

Family Medicine seeks to continue its strong tradition of publishing this highly respected journal by launching a national search for its next Editor in Chief (EIC). The EIC will guide and implement a vision for the journal that disseminates high-quality educational research and innovations to enhance care of patients, improves family medicine education, and supports family medicine faculty.

The successful applicant will be a visionary with demonstrated understanding of scientific methods, statistics, and other analytic methods, research and publishing ethics, the peer-review process, and the discipline of family medicine. They should have an outstanding record of academic and research accomplishments in family medicine and demonstrated experience with the editorial process.

A detailed job description can be found at www.stfm.org/fmeditorjobdescription

Applications must be submitted by email by November 5, 2021 and include the following materials:

- A cover letter highlighting interest and qualifications for the position

- A current curriculum vitae, including applicant's publications

- A 1-2-page description of how the editor will advance their vision for Family Medicine

- A statement from an administrator of the applicant's institution or organization describing support for the appointment

Send application by e-mail to svantuyl@stfm.org with a subject line: "Family Medicine Editor Search." 